\title{
Cost Uncertainties in Energy System Optimisation Models: A Quadratic Programming Approach for Avoiding Penny Switching Effects
}

\author{
Peter Lopion, ${ }^{a, *}$ Peter Markewitz, ${ }^{a}$ Detlef Stolten, ${ }^{a, b}$ Martin Robinius ${ }^{a}$ \\ * Corresponding author. E-mail address: p.lopion@fz-juelich.de (P. Lopion) \\ ${ }^{a}$ Institute of Electrochemical Process Engineering (IEK-3), Forschungszentrum Jülich GmbH, \\ Wilhelm-Johnen-Str., 52428 Jülich, Germany \\ ${ }^{b}$ Chair for Fuel Cells, RWTH Aachen University, c/o Institute of Electrochemical Process Engineering \\ (IEK-3), Forschungszentrum Jülich GmbH, Wilhelm-Johnen-Str., 52428 Jülich, Germany
}

\begin{abstract}
Designing the future energy supply in accordance with ambitious climate change mitigation goals is a challenging issue. Common tools for planning and calculating future investments in renewable and sustainable technologies are often linear energy system models based on cost optimisation. However, input data and the underlying assumptions of future developments are subject to uncertainties that negatively affect the robustness of results. This paper introduces a quadratic programming approach to modifying linear, bottom-up energy system optimisation models in order to take cost uncertainties into account. This is accomplished by implementing specific investment costs as a function of the installed capacity of each technology. In contrast to established approaches like stochastic programming or Monte Carlo Simulation, the computation time of the quadratic programming approach is only slightly higher than that of linear programming. The model's outcomes were found to show a wider range as well as a more robust allocation of the considered technologies than the linear model equivalent.
\end{abstract}

Keywords: Energy system modelling; uncertainties; robustness; Penny Switching Effect

\section{Introduction}

There are various concepts and ideas relating to how to design the future energy supply in order to achieve the climate goals set out in the Paris Agreement of 2015. These design concepts normally rely on energy scenarios that are influenced by various uncertainties. As a consequence, it is very challenging for decision makers to devise robust solutions to reach the afore-mentioned goals. Thus, the underlying decision-making process is supported by different types of energy system models. Most of these focus on the identification of costefficient options to supply future energy demand.[1] Due to their complexity, the models are often limited to linear programming (LP) or mixed-integer linear programming (MILP).[2, 3] However, the input data and boundary conditions for modelling future energy systems are invariably subject to uncertainties, regardless of whether simulation or optimisation models are considered.[4-6] In particular, social, climatological and technological developments constitute momentous and influential factors on the model's results.[7, 8] For example, the future investment costs of technologies are strongly related to underlying predictions of technological developments.[9, 10] Minimal changes to these assumptions on developments 
may induce marked differences in the resulting shares of technologies in the energy system. Linear cost optimisation models in particular are affected by this so-called 'Penny Switching Effect', which leads to a complete switch to other technologies through marginal variations in the corresponding investment costs.[11-13] This results in the underestimation of certain technologies or even of entire supply chains. For this reason, linear optimisation models are highly sensitive to input parameters like investment costs. Moreover, many technologies are not considered in the results of such models due to having marginally higher costs than a comparable alternative technology.

Existing solutions to overcome the described issues include, for instance, stochastic programming, Monte Carlo simulation and sensitivity analyses.[9, 14-16] All of these approaches have one thing in common, namely: they are based on a parameter variation that is accompanied by substantial computational efforts. In order to obtain more robust results with acceptable computational efforts, this paper describes an approach that aims to take investment cost uncertainties into account, with only a slight increase in the required computation time. For that purpose, a linear bottom-up energy system model for Germany is modified. Instead of a default value for specific investment costs, a cost range is implemented as a function of the installed capacity of each technology. This results in a convex quadratic objective function of the model intended to minimise the total system costs. As a consequence, the model's results are expected to comprise a wider range of technologies, be more robust and, thus, more realistic.

\section{Methods}

All of the results presented in this paper show potential for the strategy to reduce German $\mathrm{CO}_{2}$ emissions by $80 \%$ against the reference year of 1990 , taking into account both energyrelated and process-related emissions. The underlying model comprises the energy sector, as well as the end-use sectors: buildings, transport and industry. Other sectors, like the agricultural sector and greenhouse gases other than $\mathrm{CO}_{2}$, are not included. The year 2050 is chosen as the target year in this paper in order to provide an indication of the necessary transformation of the German energy system to implement the Federal Government's greenhouse gas reduction targets.

For that reason, the cross-sectoral, myopic energy system model 'FINE-NESTOR' (National Energy System model with integrated SecTOR coupling) ${ }^{*}$ is used to determine the results and the corresponding $\mathrm{CO}_{2}$ reduction strategy. The analysis of the energy system's transformation is subject to an interval of five years, starting from today's energy system and progressing up to the year 2050. Depending on the setup, this can be run in LP or QP mode based on the implementation of investment costs. The model does not consider spatial aspects of energy supply and demand, but has a flexible temporal resolution. The latter is set to an hourly basis, and so amount to 8,760 time steps. Additionally, the temporal resolution can be reduced by the aggregation of typical days. The corresponding approach is described by Kotzur et al. $(2017,2018) .[17,18]$ In this context, the intra-year use of storage technologies relies on a perfect-foresight approach. Finally, each year is individually optimised with the objective of minimising the total annual system costs.

\section{* https://github.com/FZJ-IEK3-VSA/FINE}

The underlying framework conditions of the optimisation of each year are based on historical data and the results of previously calculated years. At this point, the decommissioning of 
existing plants and a maximum annual expansion rate for each technology is taken into account. These expansion rates are based on learning curves, employment effects and technical potentials. In combination with minimum annual expansion targets based on fundamental market diffusion curves and the optimised installed capacities of the target year, the upper and lower bounds for the optimisation are determined. However, the depicted results only relate to the target year. The preceding transformation of the energy system is not considered in this analysis.

The most important underlying input data of the model is summarised in the following. Assumptions on demographic and macroeconomic developments, as well as fuel price tendencies, are primarily adopted from Buerger et al. (2016) and Gerbert et al. (2018).[19, 20] Electricity and heat demand profiles, as well as the supply profiles of $P V$ and wind power plants, are based on historical data from the year 2013. Decisive techno-economic input parameters are shown in the appendix, Table 1. This provides an abstract of around 900 components and 1500 energy and mass flows implemented in the model.

\section{Investment cost analysis}

With regard to the future energy supply being in compliance with the climate goals of the Paris Agreement, renewable energy technologies will play a key role. In contrast to fossil power generation, the output of these technologies is not bound to fuel costs. Instead, the capital expenditures (CAPEX) are the crucial factor when it comes to investment decisions. This leads to planning tools like energy system models being very sensitive towards the assumed CAPEX, which in turn are mainly affected by the initial investment.

When looking into the historical investment costs of renewable energy technologies, it is notable that the specific costs per kilowatt vary significantly. On the one hand, economies of scale, as well as the resulting increase in manufacturing efficiency have been the major influencing factors on renewable energy costs over the last decades. Other important factors that impact the actual costs of an individual technology or project relate to market pricing, auction designs, technological developments and geographical aspects.[21-23] The approach described in this paper focuses on the latter aspects. For that reason, the example of onshore wind turbines is selected for this following analysis. In order to exclude the effect of economies of scale as precisely as possible, a short and current period of time of realised investments in onshore wind turbines is the object of investigation. The resulting deviations in investment costs are depicted in Figure 1. This graphic illustrates the investment cost range and deviation of 80 wind turbines that were constructed between 2010 and 2015. Their specific investment costs per kilowatt in ascending order from low to high costs are shown in the upper left-hand corner. The minimum costs are $857 € / \mathrm{kW}$ and the maximum costs 1,613 $€ / \mathrm{kW}$. Aside from some statistical outliers marked in the red areas, there is an almost uniform distribution of the remaining values. For that reason, the tenth and ninetieth percentiles are tagged in the diagram, as well as the linear connection between these. The corresponding values are reflected in the diagram on the right. Moreover, a weighted average is given that represents the average of these percentiles. 
Figure 1. Investment cost range and deviations of onshore wind turbines, based on the IRENA Renewable Cost Database[21].
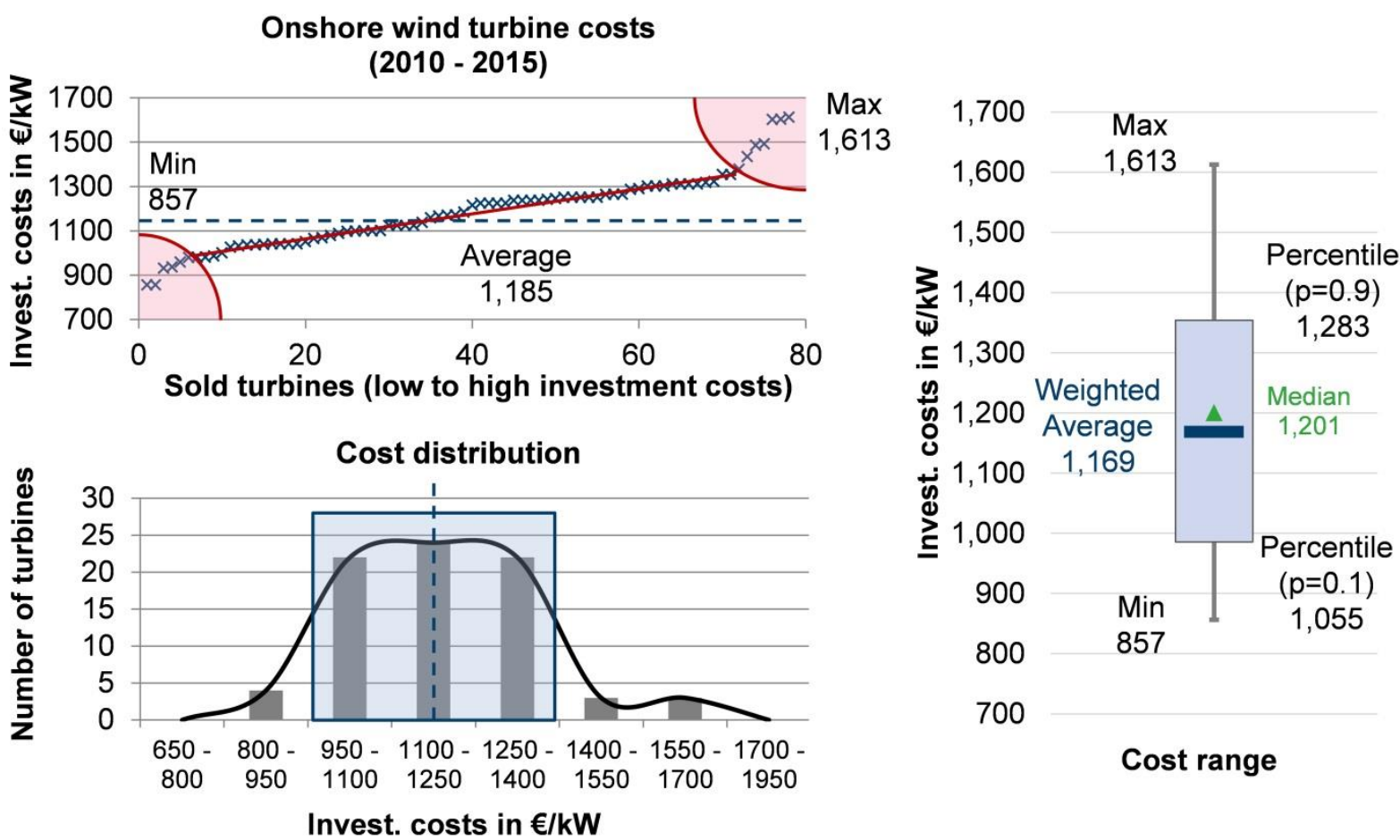

700

\section{Cost range}

Further investigations showed that the distributions of investment costs for other technologies are similar to the data for onshore wind turbines in Figure 1.[21] In particular, renewable energy technologies and end-use technologies exhibit a wide cost range with almost uniform distribution.[21] Moreover, cost trends of renewable technologies are subject to uncertainties.[24] As a result, estimations of future investment costs diverge significantly and are often indicated by ranges.[25-29]

\section{Analytical and mathematical approach}

The fact that the majority of documented investment costs are in almost uniform distribution forms the basis for the further implementation of investment costs in the model. The approach is based on the assumption that the range of investment costs for technologies can be adequately substituted by a uniform distribution. However, this coherence cannot be implemented in linear optimisation models. Common solutions are parameter variations as part of sensitivity analyses or Monte Carlo simulations. Given the complexity of most models, the initial computation time will be multiplied by the number of parameter variations due to the fact that each variation requires an individual calculation.[30, 31]

The following approach was developed in order to overcome the issue of high computational efforts, but still consider the effects of cost ranges in an energy system model. An additional requirement of the approach is that it should be possible to modify existing linear programming models. Therefore, the modified model should be solvable with common solvers like Gurobi, CPLEX or XPRESS. These solvers are just able to handle linear and quadratic equations. Due to this limitation, the simplest attempt to integrate cost spans is to define specific costs as linear functions of the model's dimensioning variables. Consequently, the objective function of the total annual costs becomes quadratic. In Figure 2, both the conventional linear and quadratic approach are compared to each other. While specific costs 
in linear models equal a constant average value, in the quadratic programming (QP) model the entire cost range described in the investment cost chapter is distributed over the installable capacity of the technology. The upper bound of the capacity variable can be either the technical potential of a technology or its expansion limit at a specific time interval. In the depicted case, the cheapest units of the technology are sold first (blue curve). This is supported by the assumption of free markets. In theory, it is also possible to implement the cost range and vice versa (dashed line), for example to consider learning curves. However, this implicates local optima in the optimisation process and cannot be solved by the solvers mentioned above. Instead, piecewise linearization can be used for an approximation of this problem.[32]

Figure 2. Comparison of the consideration of investment costs in the LP (red) and QP model (blue).
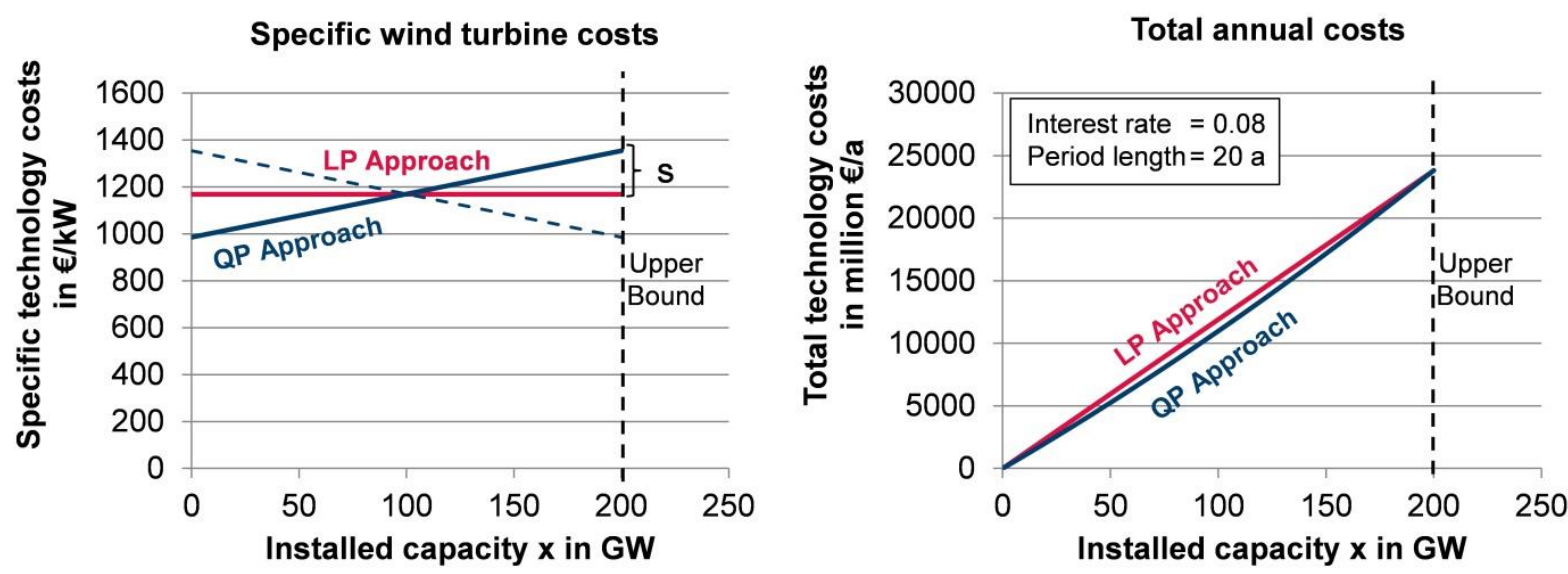

The objective function of the modified linear models is intended to minimise the total annual system costs. These costs are divided into fixed and variable costs. The fixed costs consist of CAPEX and fixed operational expenditures (fixed OPEX) $m_{f i x}$. For the determination of the CAPEX of a specific technology $y$, the capital recovery factor $r$ is utilised based on interest rate $i$ and the number of periods $n$ (Equation 1 ):

$$
r_{n, i, y}=\frac{(1+i)^{n} \cdot i}{(1+i)^{n}-1}
$$

In the linear case, the specific technology costs, $k_{L P}$, are constant and independent of the installed capacity $x$ (Equation 2). They are based on an average cost value, $C_{0}$, or a forecasted value for future scenarios. This factor, multiplied by the capital recovery factor and the fixed OPEX as a percentage of $C_{0}$ results in the fixed costs $\alpha_{L P f i x}$ (Equation 3):

$$
\begin{gathered}
k_{L P}\left(x_{y}\right)=C_{0, y} \\
\alpha_{L P f i x}\left(x_{y}\right)=C_{0, y} \cdot\left(r_{n, i, y}+m_{f i x, y}\right)
\end{gathered}
$$

Consequently, the total fixed annual costs $K_{L P f i x}$ are integral of $\alpha_{L P f i x}$ between the lower $x_{\mid b}$ and upper bound $x_{u b}$ of the capacity of technology $y$ (equations 4 and 5):

$$
\begin{gathered}
K_{L P f i x}\left(x_{y}\right)=\int_{x_{l b, y}}^{x_{u b, y}} \alpha_{L P f i x}\left(x_{y}\right) d x_{y} \\
K_{L P f i x}\left(x_{y}\right)=C_{0, y} \cdot\left(r_{n, i, y}+m_{f i x, y}\right) \cdot x_{y}
\end{gathered}
$$


The variable costs are based on energy and material flows, $k$, of the energy system in time step, $t$, which are allocated to the technologies by the ingoing and outgoing flows, $\dot{x}$. In combination with the total fixed annual costs, the objective function can be expressed, as follows, in Equation 6:

$$
\min f(x)=\min \sum_{y \in Y} C_{0, y} \cdot\left(r_{n, i, y}+m_{f i x, y}\right) \cdot x_{y}+\sum_{k \in \boldsymbol{K}} \sum_{\mathrm{t} \in \boldsymbol{T}} m_{v a r, k} \cdot \dot{x}_{k, t}
$$

In contrast to the linear approach, the specific cost function of the QP model $k_{Q P}\left(x_{y}\right)$ has a constant slope, $v$. Moreover, the average cost value, $C_{0}$, can be replaced by the weighted average value in Figure 1. The impact on the fixed costs, $\alpha_{Q P f i x}$, is explained in equations 7-9:

$$
\begin{gathered}
v=\frac{d k}{d x}=\text { const } \\
k_{Q P}\left(x_{y}\right)=v_{y} \cdot x_{y}+C_{0, y}-\frac{1}{2} v_{y} \cdot\left(x_{u b, y}-x_{l b, y}\right) \\
\alpha_{Q P f i x}\left(x_{y}\right)=k_{Q P}\left(x_{y}\right) \cdot\left(r_{n, i, y}+m_{f i x, y}\right)
\end{gathered}
$$

On the basis of these equations, the total fixed annual costs, $K_{Q P f i x}$, are described in equations 10 and 11 :

$$
\begin{gathered}
K_{Q P}\left(x_{y}\right)=\int_{x_{l b, y}}^{x_{u b, y}} \alpha_{Q P f i x}\left(x_{y}\right) d x_{y} \\
K_{Q P}\left(x_{y}\right)=\left[\frac{1}{2} v_{y} \cdot x_{y}{ }^{2}+C_{0, y} \cdot x_{y}-\frac{1}{2} v_{y} \cdot\left(x_{u b, y}-x_{l b, y}\right) \cdot x_{y}\right] \cdot\left(r_{n, i, y}+m_{f i x, y}\right)
\end{gathered}
$$

As the declaration of the specific cost slope is not especially common, the equation can be simplified by introducing the absolute deviation, $s$, of the minimum or maximum cost value from the average or weighted average cost value (see Figure 2). This leads to equation 12 for the definition of specific costs, $k_{Q P}$. Its consequences to the total fixed annual costs are shown in equations 13 and 14:

$$
\begin{gathered}
\alpha_{Q P f i x}\left(x_{y}\right)=C_{0, y} \cdot\left[\left(1-s_{y}\right)+\frac{2 s_{y}}{x_{u b, y}-x_{l b, y}} \cdot x_{y}\right] \cdot\left(r_{n, i, y}+m_{f i x, y}\right) \\
K_{Q P}\left(x_{y}\right)=\int_{x_{l b, y}}^{x_{u b, y}} \alpha_{Q P f i x}\left(x_{y}\right) d x_{y} \\
K_{Q P}\left(x_{y}\right)=\left[C_{0, y} \cdot\left(1-s_{y}\right) \cdot x_{y}+\frac{C_{0, y} \cdot s_{y}}{x_{u b, y}-x_{l b, y}} \cdot x_{y}{ }^{2}\right] \cdot\left(r_{n, i, y}+m_{f i x, y}\right)
\end{gathered}
$$

The final objective function of the QP model is shown in equation 15:

$$
\begin{aligned}
\min f(x)= & \min \sum_{y \in Y}\left[C_{0, y} \cdot\left(1-s_{y}\right) \cdot x_{y}+\frac{C_{0, y} \cdot s_{y}}{x_{u b, y}-x_{l b, y}} \cdot x_{y}{ }^{2}\right] \cdot\left(r_{n, i, y}+m_{f i x, y}\right) \\
& +\sum_{k \in K} \sum_{\mathrm{t} \in \boldsymbol{T}} \alpha_{v a r, k} \cdot \dot{x}_{k, t}
\end{aligned}
$$

For comparison of the theoretical differences in the results of the LP and QP model, Figure 3 gives a qualitative example of two similar technologies. Both represent options for the supply of the same demand. However, one technology is slightly cheaper than the other. In the linear case, the solver would only decide on the cheaper option. Lowering the specific cost of the more expensive alternative may trigger the Penny Switching Effect and completely 
change the result. Otherwise, in the QP approach both technologies would be in the solution if demand is high enough. The closer the specific cost values of the technologies, the more congruent their shares in the energy system are. As a consequence, the Penny Switching Effect can be avoided and the results become more robust.

Figure 3. Qualitative comparison of two similar technology shares in the optimised solution of the LP and QP model.
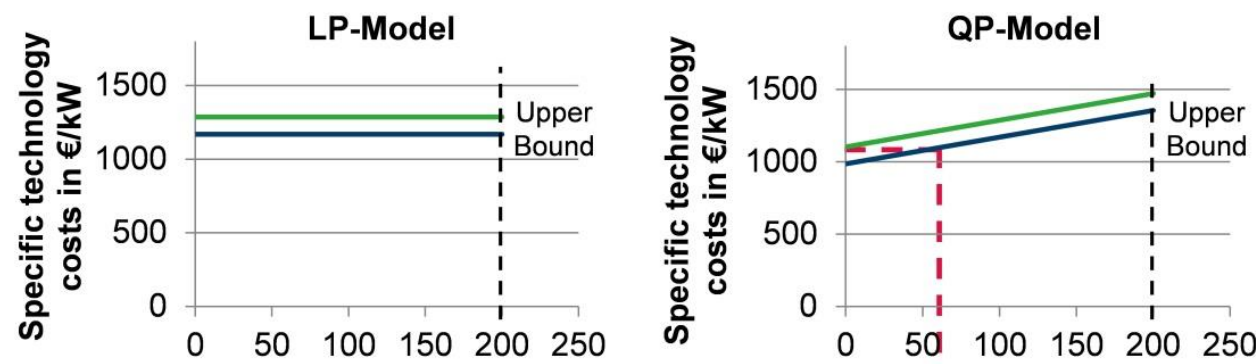

\section{Specific costs}
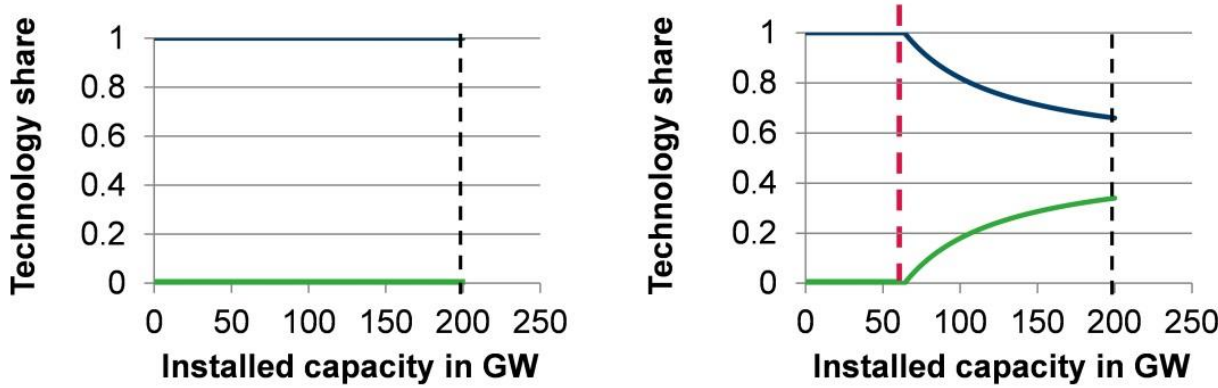

Share

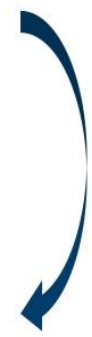

\section{Comparison of linear and quadratic programming results}

The corroboration of the hypothesis requires verification through an appropriate testing model. For verification purposes, a linear programming model for minimisation of the total energy system costs for Germany is chosen. Its temporal resolution is set to one hour, aggregated to 24 typical days.[17, 18] Spatial aspects are not considered. In this context, a potential energy system for the target year of 2050 is optimised for an $80 \% \mathrm{CO}_{2}$ emission reduction scenario, in accordance with the German 'Klimaschutzplan 2050'.[33] A detailed description of the model can be found in the methods section.

For comparison, the modified testing model is run twice, once with the linear objective function and once with the quadratic objective function. In order to illustrate the discussed theoretical impact on the results, the focus is on technologies that are sensitive to CAPEX variations. The best example of the Penny Switching Effect is the choice between commercial open field and residential rooftop photovoltaics. On the basis of the minimal lower total costs of open field PV,[26] linear energy system models tend to expand open field PV to the edge of its technical potential before building rooftop PV. Another example of this effect is the choice between onshore and offshore wind turbines. Weather and ground conditions in Germany lead to approximately doubled full load hours, accompanied by doubled costs of offshore wind turbines. These effects can be noted in Figure 4. In the linear case (red), the solution considers no rooftop PV and a nearly equal amount of onshore and offshore wind power. Instead, the quadratic case (blue) is represented by a similar share of $\mathrm{PV}$ technologies and an increase in onshore wind power. In addition, some other capacities of key technologies of the system are shown and are subject to much smaller changes. 
Figure 4. Comparison of installed capacities in the results of the LP (red) and QP (blue) model for an $80 \%$ $\mathrm{CO}_{2}$ emission reduction scenario for Germany.

Comparison of installed capacities

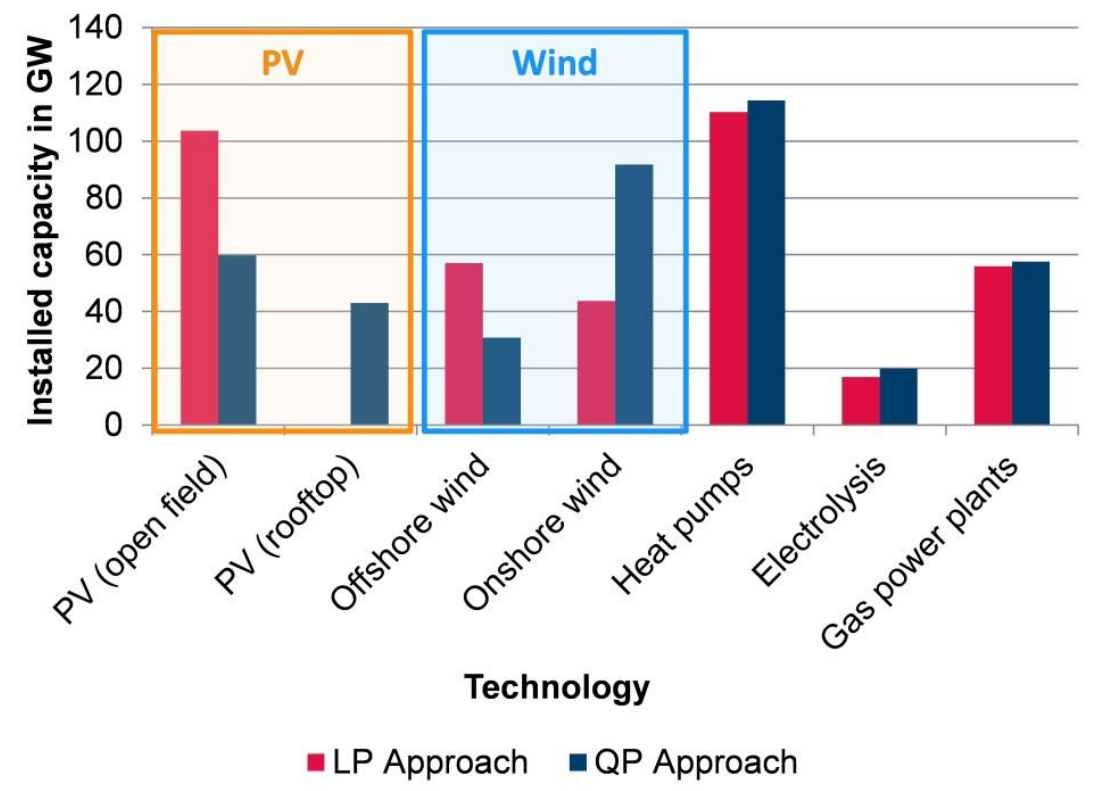

An additional conjecture of the quadratic optimisation approach is its impact on the result's robustness towards variations in the underlying investment cost parameters. For that reason, the results of a sensitivity analysis are shown in Figure 5 . This analysis is based on a variation of the offshore wind turbine investment costs by $\pm 10 \%$. In the linear model (marked in red), a massive impact on the installed capacity is registered. The decrease of the investment costs by $5 \%$ leads to an increase in capacity from $57.1 \mathrm{GW}$ in the reference case $(2,530 € / \mathrm{kW})$ up to $75 \mathrm{GW}$ that represents the upper bound in the model (based on the technical potential of offshore wind power in Germany). On the other side, a 10\% increase in the costs results in the exclusion of offshore wind in the energy system. However, the effect on the capacities is significantly reduced in the QP model, resulting in a range of $\pm 3.7 \mathrm{GW}$. 
Figure 5. Sensitivity analysis of the investment costs for offshore wind turbines and its impact on the installed capacity in the cost-optimised energy system in the LP and QP model.

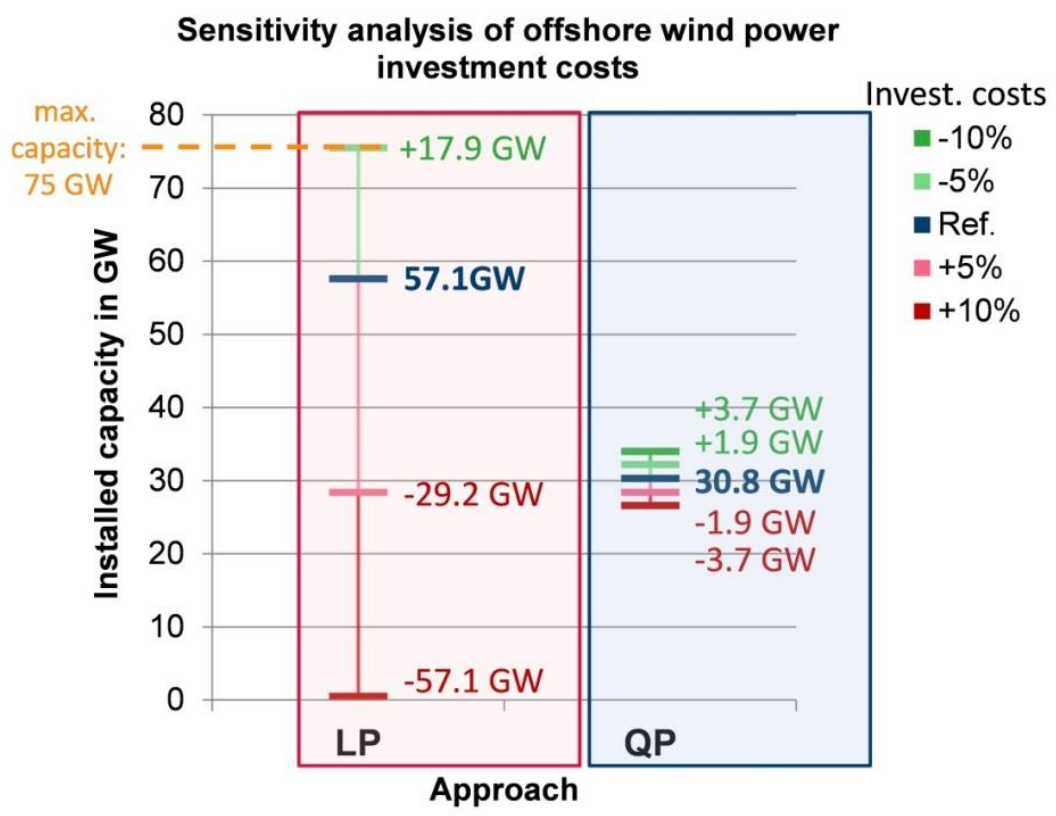

Aside from the impact on the results, it is important to take the changes in computation time using the QP approach into account. Due to the fact that the computational effort for such complex models is affected by various aspects, the change in computation time is dependent on the individual model, its input parameters, the solver and its setup. In the case of the model used for verification, the computation time of the QP model is increased by a factor of 2.04 towards the LP model. The optimisation was executed by the solver 'Gurobi'. Further investigations with different models and solver setups showed a variation in the computation time by a factor of between 0.43 and 3.68 towards the LP approach for a single year optimisation. The average value of the increase in computation time is a factor of 2.29 (median value: 2.25). When it comes to the myopic optimisation of an energy system transformation, the QP approach leads to a wider range of considered technologies. This effect can be seen in Figure 6 by the increasing number of variables of the QP models compared to the LP models. Consequently, the difference in computation time is further increased by a factor of between 1.63 and 6.13. In total, seven model configurations were analysed for testing purposes. For each configuration except the most extensive one, three single year optimisations and one transformation assessment based on seven individual optimisations were executed as LP and QP problems. The most extensive model configuration, with more than ten million variables, was only optimised for single years. 
Figure 6. Comparison of computation time of different LP and QP problems

\section{Comparison of computation time}

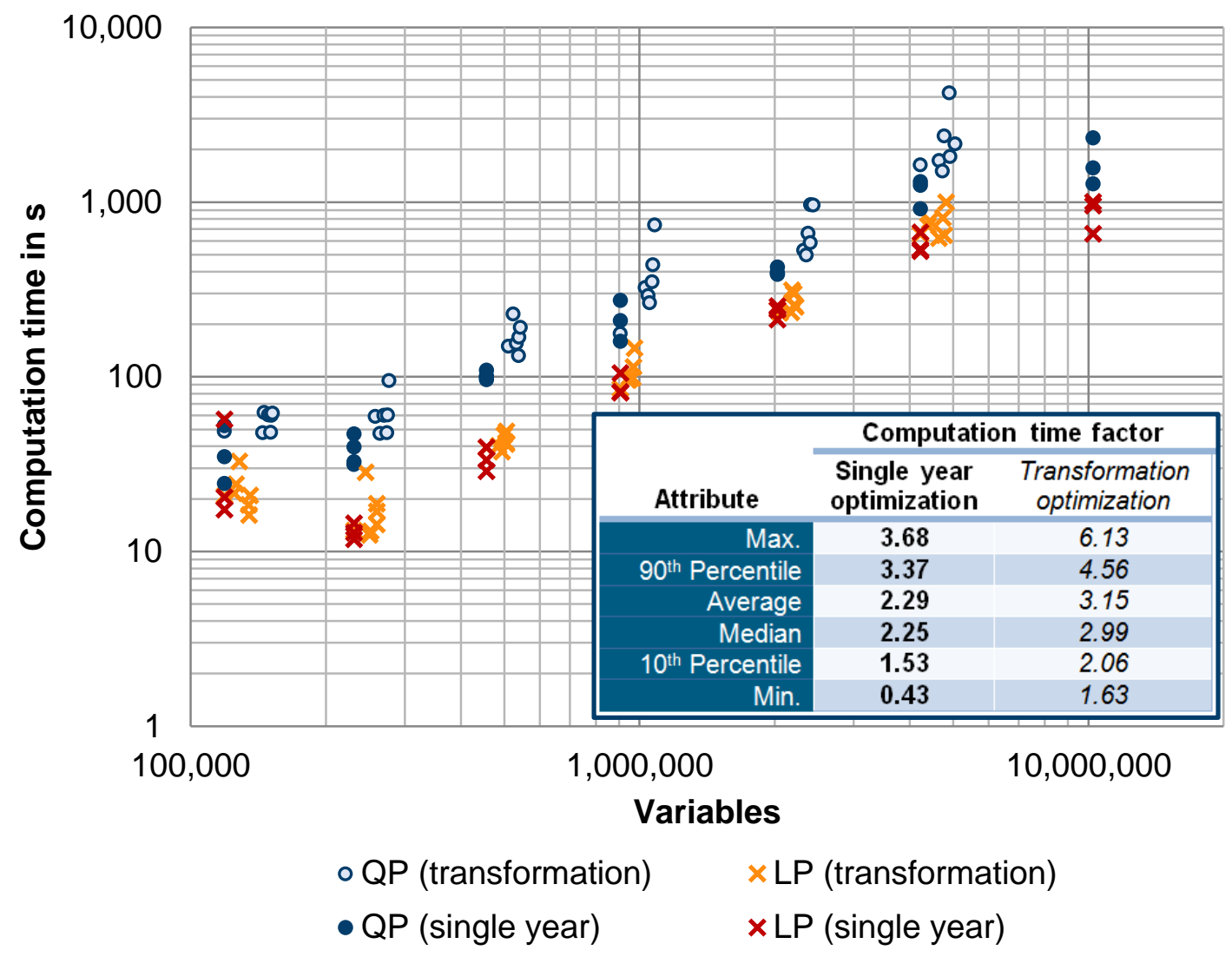

\section{Discussion and conclusions}

The preceding analysis showed that technological investment costs generally vary across wide ranges and the predictions of future trends are subject to uncertainties. Nevertheless, these cost ranges can be incorporated and simplified by implementing a quadratic objective function in conventional energy system optimisation models. In particular, models with the purpose of evaluating greenhouse gas reduction strategies that implement high shares of renewable energy in the system benefit from this approach. The investigation reveals that the results of the modified model become more robust and a broader mix of technologies is considered in the solution. Instead of penny switching effects in the LP model, the technology shares are affected much less by a variation in the specific investment costs. Moreover, when comparing the results shown in Figure 4 to the current energy system of Germany, the installed capacities of wind power and PV follow actual trends. Thus, the solution better reflects the present investment behaviour and might be described as more realistic. However, there are two effects of the QP approach that must also be discussed. Concerning the resulting total system costs, the calculated costs of the QP model are systematically lower than in the LP model if the same average value of the investment costs is implemented. This can be attributed to the fact that the average total investment costs of a technology are only equal to the linear case if the installed capacity reaches its upper bound (compare Figure 2). Either this effect is assigned to market behaviour and justified by the point of the improved implementation of markets or must be corrected by the real average 
cost value after optimisation. Aside from this effect, the results of the QP model are influenced by the definition of the specific investment cost ranges themselves. This means that the determination of the considered range, as well as the span between the lower and upper bound of installable capacity affects the result. The wider the cost range and the closer the lower and upper bound, the more the gradient of the specific technology cost curve increases. Consequently, the shares of alternative technologies become more even. This must be taken into consideration when evaluating the results.

In conclusion, the QP or MIQP approach to investment costs represents an alternative to cost minimisation in conventional LP or MILP models. The results become more robust with respect to cost uncertainties, comprise a wider range of technologies and sensitivity analyses of cost parameters can be significantly reduced by an acceptably small increase in computation time. Moreover, the approach can be easily implemented in most LP models using solvers like Gurobi, CPLEX or XPRESS. Thus, it represents an option for supporting decision makers in identifying robust key technologies and sensitive pathways in energy systems. Furthermore, the approach can be transferred to any technology in the system. In particular, the implementation of energy efficiency measures and end-use technologies, as well as in the transport and industry sector in general, has high potential to gain new insights. This should be further investigated, also to validate the presented results by other models and technologies in future. 


\section{Appendix}

Table 1. Summary of decisive techno-economic input parameters of the model.[26, 34-37]

\begin{tabular}{|c|c|c|c|c|c|c|c|c|}
\hline \multirow{2}{*}{$\begin{array}{c}\text { Component } \\
\text { Name }\end{array}$} & \multicolumn{2}{|c|}{$\begin{array}{c}\text { Specific } \\
\text { invest. costs } \\
\text { in } € / \mathbf{k W}\end{array}$} & \multicolumn{2}{|c|}{$\begin{array}{c}\text { Cost range } \\
\text { in percentage } \\
\text { deviation }\end{array}$} & \multicolumn{2}{|c|}{$\begin{array}{l}\text { Level of } \\
\text { efficiency }\end{array}$} & \multicolumn{2}{|c|}{$\begin{array}{l}\mathrm{CO}_{2} \text { emissions } \\
\text { in } \mathrm{g}_{\mathrm{co} 2} / \mathbf{k W h}\end{array}$} \\
\hline & Today & 2050 & Today & 2050 & Today & 2050 & Today & 2050 \\
\hline $\begin{array}{l}\text { Photovoltaics } \\
\text { (rooftop) }\end{array}$ & 1500 & 880 & $\pm 23 \%$ & $\pm 14 \%$ & $(1)^{*}$ & $(1)^{*}$ & 0 & 0 \\
\hline $\begin{array}{l}\text { Photovoltaics } \\
\text { (open field) }\end{array}$ & 1100 & 720 & $\pm 9 \%$ & $\pm 11 \%$ & $(1)^{*}$ & $(1)^{*}$ & 0 & 0 \\
\hline $\begin{array}{l}\text { Onshore wind } \\
\text { power }\end{array}$ & 1850 & 1250 & $\pm 30 \%$ & $\pm 36 \%$ & $(1)^{*}$ & $(1)^{*}$ & 0 & 0 \\
\hline $\begin{array}{l}\text { Offshore wind } \\
\text { power }\end{array}$ & 3920 & 2530 & $\pm 21 \%$ & $\pm 29 \%$ & $(1)^{*}$ & $(1)^{*}$ & 0 & 0 \\
\hline $\begin{array}{l}\text { Coal power } \\
\text { station }\end{array}$ & 1600 & 1600 & $\pm 9 \%$ & $\pm 9 \%$ & 0.45 & 0.48 & 890 & 840 \\
\hline $\begin{array}{l}\text { Lignite power } \\
\text { station }\end{array}$ & 2050 & 2050 & $\pm 17 \%$ & $\pm 17 \%$ & 0.42 & 0.47 & 1010 & 910 \\
\hline $\begin{array}{l}\text { Gas power } \\
\text { station }\end{array}$ & 550 & 550 & $\pm 27 \%$ & $\pm 27 \%$ & 0.40 & 0.45 & 575 & 510 \\
\hline $\begin{array}{l}\text { Biomass } \\
\text { power station }\end{array}$ & 3200 & 2080 & $\pm 22 \%$ & $\pm 21 \%$ & 0.34 & 0.38 & $(0)^{\star \star}$ & $(0)^{\star \star}$ \\
\hline $\begin{array}{l}\text { Hydropower } \\
\text { station }\end{array}$ & 5250 & 5370 & $\pm 52 \%$ & $\pm 52 \%$ & $(1)^{*}$ & $(1)^{*}$ & 0 & 0 \\
\hline $\begin{array}{l}\text { Pumped hydro } \\
\text { storage }\end{array}$ & 3000 & 3000 & $\pm 50 \%$ & $\pm 50 \%$ & $0.8^{\star \star \star}$ & $0.9^{\star \star \star}$ & 0 & 0 \\
\hline $\begin{array}{l}\text { Battery } \\
\text { storage (Li) }\end{array}$ & $\begin{array}{c}752 \\
(€ / k W h)\end{array}$ & $\begin{array}{c}246 \\
(€ / k W h)\end{array}$ & $\pm 20 \%$ & $\pm 20 \%$ & $0.9^{* * *}$ & $0.9^{\star \star \star}$ & 0 & 0 \\
\hline $\begin{array}{l}\text { Hydrogen } \\
\text { cavern storage }\end{array}$ & $\begin{array}{c}0.52 \\
(€ / k W h)\end{array}$ & $\begin{array}{c}0.52 \\
(€ / k W h)\end{array}$ & $\pm 0 \%$ & $\pm 0 \%$ & 1 & 1 & 0 & 0 \\
\hline $\begin{array}{l}\text { Electrolyser } \\
\text { (PEM) }\end{array}$ & 1564 & 500 & $\pm 21 \%$ & $\pm 21 \%$ & 0.69 & 0.7 & 0 & 0 \\
\hline Fuel cell (PEM) & 3650 & 923 & $\pm 4 \%$ & $\pm 4 \%$ & 0.49 & 0.5 & 0 & 0 \\
\hline Heat pumps & $\begin{array}{c}800 \\
\left(€ / k W_{e l}\right)\end{array}$ & $\begin{array}{c}645 \\
\left(€ / k W_{e l}\right)\end{array}$ & $\pm 38 \%$ & $\pm 38 \%$ & $\begin{array}{l}3.0 \\
(C O P)\end{array}$ & $\begin{array}{l}3.5 \\
(C O P)\end{array}$ & 0 & 0 \\
\hline
\end{tabular}

* Assumption based on the calculation of the primary energy consumption of Germany[38]

${ }^{* *}$ Assumption of neutral $\mathrm{CO}_{2}$ emissions based on the calculation of the national greenhouse gas emissions of Germany[39]

${ }^{* * *}$ Round-trip efficiency

The model's structure and parameters were validated based on historical data from the year 2013 in accordance with the integrated supply and demand profiles.

Data availability: Data available from the corresponding author upon request. 


\section{References}

[1] Lopion P, Markewitz P, Robinius M, Stolten D. A review of current challenges and trends in energy systems modeling. Renewable and Sustainable Energy Reviews. 2018;96:156-66. [2] Van Beeck N. Classification of energy models: Tilburg University, Faculty of Economics and Business Administration; 2000.

[3] Hall LMH, Buckley AR. A review of energy systems models in the UK: Prevalent usage and categorisation. Applied Energy. 2016;169:607-28.

[4] Pfenninger S, Hawkes A, Keirstead J. Energy systems modeling for twenty-first century energy challenges. Renewable and Sustainable Energy Reviews. 2014;33:74-86.

[5] Anadón LD, Baker E, Bosetti V. Integrating uncertainty into public energy research and development decisions. Nature Energy. 2017;2:17071.

[6] Ma T, Nakamori Y. Modeling technological change in energy systems - From optimization to agent-based modeling. Energy. 2009;34:873-9.

[7] McCollum DL, Zhou W, Bertram C, de Boer H-S, Bosetti V, Busch S, et al. Energy investment needs for fulfilling the Paris Agreement and achieving the Sustainable

Development Goals. Nature Energy. 2018;3:589-99.

[8] Winskel M. Beyond the disruption narrative: Varieties and ambiguities of energy system change. Energy Research \& Social Science. 2018;37:232-7.

[9] Gritsevskyi A, Nakićenovi N. Modeling uncertainty of induced technological change. Energy Policy. 2000;28:907-21.

[10] Schmidt O, Hawkes A, Gambhir A, Staffell I. The future cost of electrical energy storage based on experience rates. Nature Energy. 2017;2:17110.

[11] Held AM. Modelling the future development of renewable energy technologies in the European electricity sector using agent-based simulation: Fraunhofer Verlag; 2011.

[12] Kovacevic RM, Pflug GC, Vespucci MT. Handbook of risk management in energy production and trading: Springer; 2013.

[13] Pfluger B. Assessment of least-cost pathways for decarbonising Europe's power supply: a model-based long-term scenario analysis accounting for the characteristics of renewable energies: KIT Scientific Publishing; 2014.

[14] Connolly D, Lund H, Mathiesen BV, Leahy M. A review of computer tools for analysing the integration of renewable energy into various energy systems. Applied Energy. 2010;87:1059-82.

[15] Bosetti V, Marangoni G, Borgonovo E, Diaz Anadon L, Barron R, McJeon HC, et al. Sensitivity to energy technology costs: A multi-model comparison analysis. Energy Policy. 2015;80:244-63.

[16] Seljom P, Tomasgard A. Short-term uncertainty in long-term energy system models - A case study of wind power in Denmark. Energy Economics. 2015;49:157-67.

[17] Kotzur L, Markewitz P, Robinius M, Stolten D. Time Series Aggregation for Energy System Design: Modeling Seasonal Storage. arXiv preprint arXiv:171007593. 2017.

[18] Kotzur L, Markewitz P, Robinius M, Stolten D. Impact of different time series aggregation methods on optimal energy system design. Renewable Energy. 2018;117:474-87.

[19] Bürger V, Hesse T, Quack D, Palzer A, Köhler B, Herkel S, et al. Klimaneutraler Gebäudebestand 2050. On behalf of the German Environment Agency Climate Change. 2016;6:2016.

[20] Gerbert P, Herhold P, Burchardt J, Schönberger S, Rechenmacher F, Kirchner A, et al. Klimapfade für Deutschland. Bundesverbandes der Deutschen Industrie (BDI). 2018.

[21] Renewable Power Generation Costs in 2017. IRENA (2018), International Renewable Energy Agency, Abu Dhabi. 2018.

[22] Drechsler M, Egerer J, Lange M, Masurowski F, Meyerhoff J, Oehlmann M. Efficient and equitable spatial allocation of renewable power plants at the country scale. Nature Energy.

2017;2:17124.

[23] Afanasyeva S, Saari J, Kalkofen M, Partanen J, Pyrhönen O. Technical, economic and uncertainty modelling of a wind farm project. Energy Conversion and Management.

2016;107:22-33. 
[24] Rout UK, Blesl M, Fahl U, Remme U, Voß A. Uncertainty in the learning rates of energy technologies: An experiment in a global multi-regional energy system model. Energy Policy. 2009;37:4927-42.

[25] Pure power-wind energy targets for 2020 and 2030: Ewea, European Wind Energy Association; 2011.

[26] Carlsson J. Energy Technology Reference Indicator projections for 2010-2050.

European Commission, Joint Research Centre, Institute for Energy and Transport Luxembourg. 2014;10:057687.

[27] Roadmap E. 2050: a practical guide to a prosperous, low carbon Europe. Brussels: ECF. 2010.

[28] Taylor M, Ralon P, llas A. The power to change: solar and wind cost reduction potential to 2025. International Renewable Energy Agency (IRENA). 2016.

[29] MacDonald M. Costs of low-carbon generation technologies. Report for the Committee on Climate Change Brighton, Mott MacDonald. 2011.

[30] Creutzig F, Agoston P, Goldschmidt JC, Luderer G, Nemet G, Pietzcker RC. The underestimated potential of solar energy to mitigate climate change. Nature Energy.

2017;2:17140.

[31] McCollum DL, Jewell J, Krey V, Bazilian M, Fay M, Riahi K. Quantifying uncertainties influencing the long-term impacts of oil prices on energy markets and carbon emissions. Nature Energy. 2016;1:16077.

[32] Heuberger CF, Rubin ES, Staffell I, Shah N, Mac Dowell N. Power capacity expansion planning considering endogenous technology cost learning. Applied Energy. 2017;204:83145.

[33] Bundesministerium für Umwelt N, Bau und Reaktorsicherheit. Klimaschutzplan 2050Klimapolitische Grundsätze und Ziele der Bundesregierung. 2016.

[34] Saba SM, Müller M, Robinius M, Stolten D. The investment costs of electrolysis - A comparison of cost studies from the past 30 years. International Journal of Hydrogen Energy. 2018;43:1209-23.

[35] Noack C, Burggraf F, Hosseiny S, Lettenmeier P, Kolb S, Belz S, et al. Studie über die Planung einer Demonstrationsanlage zur Wasserstoff-Kraftstoffgewinnung durch Elektrolyse mit Zwischenspeicherung in Salzkavernen unter Druck. German Aerospace Center:

Stuttgart, Germany. 2015.

[36] Welder L, Ryberg DS, Kotzur L, Grube T, Robinius M, Stolten D. Spatio-temporal optimization of a future energy system for power-to-hydrogen applications in Germany. Energy. 2018;158:1130-49.

[37] Stolzenburg K, Hamelmann R, Wietschel M, Genoese F, Michaelis J, Lehmann J, et al. Integration von Wind-Wasserstoff-Systemen in das Energiesystem. Analysis on behalf of Nationale Organisation Wasserstoff-und Brennstoffzellentechnologie GmbH (NOW). 2014.

[38] Energiebilanzen 1990-2016. Berlin, Germany: AGEB1990.

[39] Harthan RO, Hermann H. Sektorale Abgrenzung der deutschen

Treibhausgasemissionen mit einem Schwerpunkt auf die verbrennungsbedingten CO2-

Emissionen. Öko-Institut eV, Berlin. 2018. 